no interference can be made with their prescribing over the counter; but I think there should be full power to prevent their visiting patients, or assuming and using the title of physician, surgeon, apothecary, or general practitioner. I do not believe that excluding druggists from all medical appointments, and from all legal claim to remuneration, will give any check to their injurious pursuits-but, on the contrary, without penal restriction, the druggist will become more and more the apothecary, and will associate and connect himself with the prescriber of medicines, whether physician or surgeon, in a way detrimental to the public, just in proportion as the general practitioner seeks to be promoted.

The medical care of the poor seems likely to be placed on so improved a footing, that I do not desire to dilate upon this subject, and have no room.

The most difficult of all subjects is, pcrliaps, quackery, whether professional or extra-professional ; the former is by far the worse, but can only be restrained by licensing bodies having the power, under extreme circumstances, of withdrawing their diploma and placing the delinquent beyond the pale of the profession. For quacks of the latter class, which the public have had in all ages, and will always have, I do not fecl competent to suggest iny further restriction than precluding the quack from assuming the title of physician, surgeon, general practitioner, apothecary, \&c., or using any advertisement or inscription calculated to delude the public into a belief that he belongs to the medical profession.

A Member of the Provincial Association.

To Dr. Hastings, Secretary to the

Prov. Med. and Surg. Association.

\section{CERTIFICATES OF INSANITY.}

TO THE EDITORS OF THE PROVINCIAL MEDICAL JOURNAL.

Gentlemen,-Having observed in the last number of your periodical, from the pen of a correspondent, that Lord Granville Somerset, on presenting the proposed new "Bill for regulating Lunatic Asylums" to the House of Commons, stated his intention to take away from the surgeon and apothecary the power to sign certificates of insanity, and confer such power only on " members of the College of Physicians," I immediately addressed the noble lord on the subject, and am glad to be able to quote his reply to the effect that " no intention was ever entertained to alter the descriptions of medical practitioners by whom certificates of insanity may now be signed." It is sufficiently clear that every practitioner legally authorised to exercise his profession ought to have the power referred to, and the ridiculousness of the idea of restricting it to members of the London College of Physicians throughout England cannot be placed in a more prominent light than by the fact which my own knowledge enables me to state publicly, that amongst a population of above 700,000 inhabitants in this eastern district there are not now practising half a dozen members of the College of Physicians. In the city where I reside there is at this day, amongst a population of above 70,000, only one licentiate of the College

of Physicians resident and practising, and he two years ago was a general practitioner, having been recently admitted an extra licentiate in consequence of the new and more liberal regulations of the college; to this promotion he proves himself, I believe, every way entitled, save that he embraces opportunities both in private and in public to cast reflections on the line of practice he has so recently quitted.

I remain, Gentlemen,

Your obedient servant,

Norwich, April 6, 1842. J. G. Crosse.

TO THE EDITORS OF THE PROVINCIAL MEDICAL JOURNAL.

Gentiemen,-I herewith forward to you a copy of a letter I addressed to Lord Granville Somerset, and his lordship's reply, reppccting the medical ccrtificates of admission to lunatic asylums, the substance of which, if inserted in your widely-circulated Journal, will correct much misapprehension.

Your obedient servant, G. W. DYKE.

" My Lord,--Many communications have doubtless been addressed to your lordship on the subject of the bill which you have recently introduced to amend the law relating to lunatic asylums, more especially to the clauses by which (if the newspapers are correct) it is proposed that in future the medical certificates of admission shall be signed by members of the College of Physicians of London only. I beg leave to inform your lordship that in the county of Wilts there are six asylums for the insanc, four of which I believe contain upwards of one hundred patients, and that there is not, to the best of my knowledge, one member of the College of Physicians of London practising in the county. Your lordship can, therefore, readily conceive the trouble and expense to which those parties will be put who are desirous of sending patients to those institutions, provided this part of the bill is not altered in committee.

*

Corsham, Wilts, April 6, 1842."

"Clarges-street, April 7, 1842.

Sir,-The bill which I have introduced into Parliament contains no clause to alter the existing law as to certificates of insane patients. I gave the subject much consideration, and I did not think upon the whole that I could make an alteration without producing greater evils than benefits.

I am, Sir, yours, \&c., G. C. H. Somerset.

Dr. Dyke, M.D."

\section{GLOUCESTERSHIRE LENT ASSIZES.}

PRESCRIBING DRUGGISTS.

The following important trial will, we trust, set at rest the hitherto disputed question between chemists 
and medical practitioners. We have abridged the account from the Cheltenham Examiner of April 6 :-

THE MASTERS AND WARDENS OF THE SOCIETY OF APOTHECARIES $v$. ROBERTS.

This was an action to recover penalties alleged to have been incurred by the defendant by practising as an apothecary without the certificate of qualification required by the 55 th George III., c. 194 .

Mr. Maclean having opened the pleadings,

Mr. Scrjeant Talfourd addressed the jury. In consequence of the greatimportance which this class of medi- cal practitioners had assumed, it became cxtremely necessary to guard the health of the public against the intrusion of persons into that branch of the profession who should be unfitted to perform the duties attaching to it, and accordingly in the year 1815 an Act of Parliament was passed, which reposed in the Society of Apothecaries, an ancient body-ohored by King James I., and its sworn examiners, the duty of superintending the education, and testing the qualification of those who should thereafter engage in the practice of an apothecary. I cannot do better than read you the terms of the Act of Parliament itself. It recites, "That much mischief and inconvenience has arisen from great numbers of persons in many parts of England and Wales exercising the functions of an apothecary who are wholly ignorant and utterly incompetent to the exercise of such functions, whereby the health and lives of the community are greatly endangered, and it is become necessary that provision should be made for remedying such evils." Then that mischief being recited, the Act of Parliament enacts, "That the said master, wardens, and Society of Apothecaries, and their successors shall be, and they are hereby appointed and constituted, directed, aid empowered, for ever to superintend the exccution of the provisions of this $\Lambda$ ct, and to enforce and carry the several regulations and provisions thereof in relation to the several persons practising the art and mystery or profession of an apothecary throughout England and Wales, and all other purposes of this Act into full exccution." Another clause prohibits any persons from practising as apothecaries, unless they shall have obtained a certificate from the Society of Apothecaries, which of course is preceded by an examination by persons appointedjby the Society, and enacts that persons practising without such certificate, shall be liable to a penalty of $£ 20$ for each offence, and empowers the Society of Apothecaries to sue for that penalty. It does not permit (as is often the case) any individual who may think fit to take npon himself the enforcement of the law, either for his own personal and individual benefit, or from any other fceling, but reposes in the Society alone the power of instituting proceedings like that which has brought the defendant, Mr. Roberts, before you to-day. $\mathbf{M r}$. Charles Roberts carries on the business of a chemist and druggist, in Winchcomb-street; in the town of Cheltenham, and in the month of January, 1841, it was brought to the notice of the society, that he had taken upon himself to act as a medical practitioner, that he had attended patients in various illnesses, and had not only provided drugs, but had given his advice, and had, in fact, performed all those functions, wl ch in modern times have belonged to an apothecary. A letter was accordingly addressed by the society to $\mathrm{Mr}$. Roberts in that month, informing him they had received such information, and desiring him to desist for the future, or that they should put the law in force against him. They heard nothing from him, however ; but in December last (many months having elapsed), certain procecdings took place in Cheltenham, which of necessity brought it to the knowledge of the Society, that Mr. Roberts had been acting, and acting somewhat extensively too, in prescribing for, and in administering medicines to the poorer class of the community; and when it was brought to the knowledge of the Society in such a manner they felt bound (their previous warning having been disregarded) to institute these proceedings. They found several cases, when they came to inquire further, in which be had given his advice, and attended as a medical man, and acted, in fact, precisely as apothecaries aot, with this slight difference, that his charge had been made nominally for his medicines, only a difference which does not exist in the case of many apothecaries, it having been, indeed, till lately thought that an apothecary had no right to make a separate charge for his attendance, a very unfortunate delusion, which has now been happily removed. Under these circumstances the present action has been brought against $\mathrm{Mr}$. Roberts. Perhaps he may have proceeded upon this ground-he is a chemist and druggist, a trade which borders on the margin of the medical profession, but for the purpose of entering into which there is no previous examination, education, or even necessary skill; any person who chooses to open a shop in any town, to put "chemist and druggist" over his door, and to get some large glass bottles filled with prettily coloured liquor, may hold himself out to the world and act as a chemist and druggist; and most useless would this Act of Parliament be if a person who carried on this extremely respectable trade, even if he carried it on boni fide, had a right to break through the provision of the law and to practice as an apothecary. $\mathrm{Mr}$. Roberts has been probably urider an impression that he had a right to act $i$ that manner, and that impression he may have derived in part from the circumstance of a trial which took place before a learned judge, who was once a great ornament to the bar of this eircuit (Mr. Justice Maule), in which the jury acted under the direction of that larned judge, who thought that an exception contained in this Act of Parliament in favour of the trade of chemists and druggists, allowing them to carry on that trade as before the Act, might entitle a chemist and druggist to giveadvice and to administer medicine, but that was afterwards set right by the Court of Quecn's Bench, and it is now well kuown and established that the carrying on the trade of a chemist and druggist gives no right to an uneducated and unauthorised person to act as an apothecary. I am willing to give Mr. Roberts credit of having been confirmed in the course he was taking by $_{\mathbf{b}}$ an apprehension of that kind. I believe that my friend, Mr. Alexander, who appears for Mr. Roberts, is ready, on his behalf, to express his regret for having violated the law, to admit that he has so done, and that there is no foundation at all, when the matter is rightly investigated and understood, for the claim of a chemist and druggist to act as an apothecary without a proper certificate from the 
Society. If my learned friend is now instructed to express that fecling on the part of the defendant, then I, on the part of the Society of Apothecaries, am content to accept your verdict for one penalty, and to $a b$ stain from enforcing that judgment or the costs upon it, unless the Society shall satisfy themselves that he has again infringed the law; in which case the judgment will be put in force against him. The Society will not exercise the power they thus reserve to themselves without the most candid and full examination. I firmly hope and believe that there will never be any occasion for such an examination, but that Mr. Roberts, convinced of his error and acknowledging it now through his courisel, will cease to act as he has done, and then the object will be accomplished which induced the Society to bring this case before you.

Mr. W. Alexander for the defendant then said: I am anxious to express, both on the part of Mr. Roberts and myself, my full conviction of the pure motives which have actuated the plaintiffs in this proceeding. I believe they have been actuated only by a sense of their public duty. Mr. Roberts desires me to express on his behalf his regret for having broken the law, as he is now aware he has done, by violating the provisions of the Apothecaries' Act. The mistake into which he has inadvertently fallen arose from the very general way in which a decision in the case of the A pothecaries' Company $v$. Greenough was transmitted through the country i- 2 various medical works, and the length of time which elapsed before the verdict in that case was set right by the Court of Queen's Bench. He regrets that he broke the law, and he is not at all unwilling to submit to the terms which have been suggested, and to consent to a verdict passing against him for one penalty, and he engages bonu fide to abstain from the practice of an apothecary in future.

Mr. Justice Patteson : I am glad the case has taken th: s course, for I can very casily see the effect that that case to which you refer must have had between the time of the verdict and the time of its being set right by the Court of Queen's Bench. The doubt arose from the word "dispense," which is used in the 28 th section. That is the clause authorising chemists to dispense medicine, and it was thought that that meant that they might give advice, but the court determined that it gave no such power.

The verdict was then taken for one penalty and costs, and the jury were discharged as to the other counts.

\section{Artrospet of the ftedical Sriences.}

THE CaUses of METallic TINKLING.

Laer rec, whose talent for observation exceeded his powers of explanation, gave a very vague theory of the cause of metallic tinkling. Dance attributed it to the breaking of the bubbles of air on the surface of the liquid in the pleural cavity. M. Beau adopted this explanation, and sought to render it complete by adding the cases in which the fistula, not opening below the level of the liquid, traverses a collection of puislent matter; and finally, M. Raciborski explains metallic tin'.'ing by the vibrations of the effused fluid, caused by the motions of respiration, the cough, and the voice. M. de Castelnau, availing himself of the arguments used by Messrs. Barthe and Rogers, in their Manual of Auscultation, has easily demonstrated the "isufficiency of each of these theories taken separately. In fact, the theory of Messrs. Dance and Beau falls at once before the well-ascertained fact, that the titikling has been observed in cases where the fistula opened above the level of the liquid; on the other hand, besides the difficulty of understanding the theory of Raciborski, if it were founded in truth, the metallic tinkling, as de Castelnau observes, ought to be present also in pneumo-hydro-thorax without communication, which does not occur, in at least the great majority of cases. M. de Castelnau considers the metallic tinkling to be nothing else than a mucous or cavernous rale resounding in a spacious cavity, by means of a communication established between it and the bronchia-that is to say, an amphoric râle. The presence of a liquid, he adds, is not necessary for its appearance. He supports his theory by experiments and clinical observations.

An elastic gum catheter, containing a few drops of water, or mucilage, to moisten its parietes, was affixed to a syringe, the piston of which was set in action; a species of râle, closely resembling the mucous râle, was then heard. The end of the catheter was next introduced into a vessel of a certain size-a bottle or pitcher, for example-and the rûle was immediately changed into a genuine metallic tinkling, which was heard equally well when the bottle was empty, as when it contained fluid. This experiment was repeated on the dead body, and the same results were obtained. The clinical facts are four in number, and three of these, at least, prove that metallic tinkling can exist without the air being obliged to traverse a liquid in the pletural cavity.-Examinateur Médical.

\section{PHTHISIS.}

Of ninety-eight patients who have been, or are, under my care since the beginning of October, no fewer than twenty-eight (which is one in three and a half) have presented signs of tubercles in the lungs. Of this number, thirteen were cases either of latent phthisis, or of pulmonary tubercles disguised by other diseases, and which, but for their physical signs, we should not pronounce (perhaps not even suspect) to be tuberculous at all. I am convinced, from extensive observations and much reflection on this sub. ject, that tuberculous disease of the lungs, in some degree or form of ariother, prevails among the more scriously sick in London, and in other large towns, in as great proportion as among our own patients (above stated). So far as our post-mortem examinations have given the opportunity, you have seen verified the statement which you have often heard me make - that of those in large towns, who die of various diseases or accidents, above the age of thirty, more than half exhibit in the lungs more or less of tuberculous disease, or of the traces which it leaves behind. It is thus only we can learn the real amount and importance that tuberculous disease bears in the scale of maladies, by regarc'ng it not only in its more acknowledged forms, and attended by its common symptoms, but by aid of careful physical diagnosis, or of the still more minute search of the scalpel, tracing it in all its 